\title{
Elementos de gamificação presentes em Livros Literários Infantis digitais interativos em formato de Aplicativo (LLIA): análise de práticas multiletradas na formação de leitores
}

\author{
Paulo Henrique Machado ${ }^{1}$ \\ Maria de Lourdes Rossi Remenche ${ }^{2}$
}

Programa de Pós-Graduação em Estudos de Linguagens, Universidade Tecnológica Federal do Paraná, Curitiba, PR, Brasil

Resumo: O presente estudo tem como objetivo analisar as práticas multiletradas mobilizadas pelos elementos de gamificação presentes em Livros Literários Infantis digitais interativos em formato de Aplicativos (LLIA) que contribuem para a formação do leitor literário na infância. Para tanto, delimitou-se como corpus de pesquisa LLIA finalistas do BolognaRagazzi Digital Award (Itália) no ano de 2016 e do Prêmio Jabuti (Brasil) na categoria "Infantil Digital" nos anos de 2015, 2016 e 2017. Trata-se de pesquisa qualitativo-interpretativista, cujo arcabouço teórico-metodológico ancora-se nos estudos dos multiletramentos, da literatura infantil digital, da gamificação, entre outros. Identificou-se que na relação entre as narrativas dos LLIA e os elementos de gamificação, estes contribuem para deixar os enredos mais emocionantes, pois os roteiros das histórias contemplam níveis progressivos, desafios, missões, busca por recompensas e retroalimentações, que possibilitam maior integração dos conteúdos com o imaginário do leitor, oportunizando que este leia em seu próprio ritmo.

Palavras-chave: Literatura infantil; Livros digitais interativos; Multiletramentos; Gamificação.

Title: Elements of Gamification presents in Children's Literature Book Apps: Analysis of multiliteracies practices in the readers' formation

Abstract: The present study aims to analyze the multiliteracies practices mobilized through gamification in Children's Literature Book Apps that contribute to the formation of the literary reader in childhood. Being that, the following book apps were chosen as a corpus: the finalists of the BolognaRagazzi Digital Award (Italy) of the year 2016, the Jabuti Award (Brazil) in the category "Digital Infancy" of the years 2015, 2016 and 2017. It is qualitativeinterpretative research, which theoretical-methodological framework is anchored in the studies of multiliteracies, digital literature for children, gamification, among others. After analyzing the material, it was identified that the enlightenment between the book apps narratives and the gamification elements contributed to make the plots more exciting,

\footnotetext{
${ }^{1}$ Mestre em Estudos de Linguagens pela Universidade Tecnológica Federal do Paraná (UTFPR). Gestor da Informação na Prefeitura Municipal de Curitiba. Orcid: https://orcid.org/0000-0002-6459-7526

E-mail: phenrique14@yahoo.com.br

${ }^{2}$ Doutora em Linguística pela Faculdade de Filosofia, Letras e Ciências Humanas da Universidade de São Paulo (USP). Docente do Programa de Pós-Graduação em Estudos de Linguagens (PPGEL) da Universidade Tecnológica Federal do Paraná (UTFPR). Orcid: https://orcid.org/0000-0003-3283-9890

E-mail: mremenche@utfpr.edu.br
} 
since the scripts of the stories contemplated progressive levels, challenges, quests, search for rewards and feedbacks. Those resources allow readers to be integrated with the contents, providing not only the opportunity for them to use their imagination, but also to read at their own pace.

Keywords: Children's literature; Interactive digital books; Multiliteracies; Gamification.

\section{Considerações iniciais}

As Tecnologias Digitais de Informação e Comunicação (TDIC) permitem criar sistemas computacionais desenvolvidos para interagirem com pessoas, embutidos nos mais diferentes dispositivos eletrônicos, que combinam poder computacional e meios de comunicação. Elas possibilitam a criação de materiais dinâmicos e interativos que favorecem o aprendizado e a transformação da noção de distância e tempo na comunicação entre pessoas, por exemplo. Os sistemas computacionais interativos adquirem importância significativa não apenas pelo seu valor comercial, mas, principalmente, pelos seus efeitos no dia a dia das pessoas. Esses aspectos reunidos promovem a vivência de novas formas de utilização da linguagem, e, consequentemente, geram alterações nas formas de ler e escrever nos diferentes espaço-tempos propiciados pela cibercultura.

Os textos hodiernos apresentam recursos atrativos e interativos, diversificando-se na forma e no conteúdo com elementos de natureza multissemiótica. As diversas semioses que constituem esses textos acionam práticas multiletradas como, por exemplo, a apropriação de recursos tecnológicos para a prática de leitura. À medida que surgem novas tecnologias, diferentes formas de ler, de escrever e de se relacionar vão se constituindo. Tal dinâmica evidencia que os avanços tecnológicos contribuem para mudanças significativas dessas práticas em ambiente digital.

Nesse cenário de transformações, os livros têm passado por mudanças em seu funcionamento, forma e função, que afetam não só aos leitores diretos, como toda sociedade. No contexto da convergência digital promovido pelas TDIC, verifica-se que o livro de literatura infantil impresso, que por tempos se manteve como o principal suporte dos textos verbais, visuais e verbovisuais, enfrenta a concorrência de formatos digitais (e-books) que incorporam múltiplas semioses e possibilitam novas formas de interação textos-sujeitos, impactando, sobretudo, nos processos de leitura e de letramento literário. Emerge, portanto, uma produção literária específica da virtualidade, criada pelo uso de computador e geralmente lida em telas, denominada literatura digital ou eletrônica, que de acordo com Hayles (2009, p. 21) "é movida pelos motores da cultura contemporânea, especialmente jogos de computador, filmes, animações, artes digitais, desenho gráfico e cultura visual eletrônica."

Esses livros digitais interativos surgem principalmente em formato de aplicativos para dispositivos eletrônicos portáteis com telas sensíveis ao toque (tecnologia touchscreen) - daí deriva o nome "livro aplicativo" ou "book app", em inglês, nominados nesta pesquisa como 
Livros Literários Infantis digitais interativos em formato de Aplicativos (doravante, LLIA). O livro aplicativo consiste em software desenvolvido para ser acessado em sistemas operacionais específicos (iOS e Android, por exemplo), permitindo utilizar recursos e capacidades desses sistemas. Dessa forma, oferece ao leitor/agenciador/usuário mais possibilidades interativas que os livros digitais em formato de arquivo, os quais necessitam de software preexistente para seu funcionamento.

Kirchof (2009) relata que várias narrativas digitais, ao mesmo tempo em que colocam percursos diferenciados de leitura à disposição do leitor, também exploram a hibridação semiótica entre sons, imagens e movimentos, utilizando recursos típicos de outras mídias (transmedia), sendo que as aproximações mais intensas têm ocorrido entre o campo literário e o campo dos jogos digitais ao ponto de, muitas vezes, ser difícil decidir se a obra em questão é um game ou uma narrativa literária. Os desafios inseridos na experiência da narrativa fazem com que a leitura nesses artefatos possa ser englobada na esfera de experiências gamificadas.

Nessa perspectiva, esta pesquisa tem como objetivo analisar as práticas multiletradas mobilizadas pelos elementos de gamificação presentes em LLIA que contribuem para a formação do leitor literário na infância.

Selecionou-se o corpus de pesquisa dentre os LLIA finalistas do BolognaRagazzi Digital Award (Feira do Livro Infantil de Bolonha, Itália) no ano de 2016 - "Wuwu \& Co.", "Chomp" e "Goldilocks and Little Bear" - e do Prêmio Jabuti (Câmara Brasileira do Livro) na categoria "Infantil Digital" nos anos de 2015, 2016 e 2017 - "A trilha", "Flicts" e "Monstros do cinema".

Trata-se de pesquisa qualitativo-interpretativista, cujo arcabouço teóricometodológico se apoia nos estudos da literatura infantil digital, dos livros digitais interativos, dos multiletramentos, dos estudos sobre gamificação, entre outros.

Apresenta-se na sequência um breve percurso das perspectivas teórico-conceituais (seção 2). Posteriormente, evidencia-se o percurso metodológico da pesquisa (seção 3), seguido da apresentação e discussão dos resultados (seção 4). As considerações finais compõem a seção 5, que apresenta síntese da investigação descrita neste estudo.

\section{Elementos de gamificação e a leitura de LLIA}

A leitura consiste em atividade multifacetada e multidimensional, diretamente relacionada com cinco processos: neurofisiológico, cognitivo, afetivo, argumentativo e simbólico (JOUVE, 2002). É uma atividade plural, complexa, que se desenvolve em várias direções e que pode ser estudada e compreendida por meio de diversos enfoques. Essencialmente, ela consiste no compartilhamento dos sentidos de uma sociedade e o ato 
de ler "é um processo que, qualquer que seja o seu ponto de partida teórico, passa necessariamente pelo leitor, autor, texto e contexto. Sem um deles, o circuito não se completa e o processo resulta falho." (COSSON, 2014, p. 41).

$\mathrm{O}$ ato de ler compreende práticas reais e significativas de leitura, que envolvem diversos procedimentos e capacidades, todas dependentes da situação e das finalidades de leitura, denominadas "estratégias (cognitivas, metacognitivas)" (ROJO, 2009, p. 75), as quais privilegiam o acesso das crianças a textos literários de qualidade, auxiliando-as na ampliação da compreensão do que é lido, fazendo-as apropriar-se da cultura e avançar a patamares mais elevados de humanização. Por consequência, o processo de formação de leitores está interligado à literatura infantil, cuja importância no desenvolvimento psicossocial da criança e no processo de aprendizagem tem incitado estudos concernentes à sua função de aprimorar no leitor o gosto e a prática da leitura em diferentes linguagens e suportes.

A criança de hoje lê, vê, aprende e pensa o mundo de forma diferente, uma vez que recebe uma multiplicidade de informações representadas em diferentes linguagens. Da mesma maneira, os livros de literatura infantil, como artefatos dinâmicos, se atualizam constantemente, pois estão direcionados a essa criança.

A literatura infantil tem experimentado, continuamente, transformações de diversos tipos. Quanto à criação de conteúdo digital, a Internet e os computadores apareceram numa primeira leva, no entanto, foram os avanços tecnológicos dos últimos anos, a partir da popularização de tablets, smartphones, e leitores eletrônicos, que fizeram disparar a criação e difusão das obras infantis concebidas para serem lidas em telas, assim como o debate sobre a sua pertinência (TURRIÓN, 2014).

Na contemporaneidade, o livro literário infantil digital caracteriza-se, portanto, pelo hibridismo e pelo uso de recursos multimodais, pois expande as narrativas verbovisuais peculiares ao livro ilustrado impresso por meio da incorporação das dimensões auditivas, táteis e performativas, ou seja, aos textos são incorporados sons, imagens em movimento e interatividade por meio do tato. Existem diversos formatos e propostas de livros digitais para o público infantil, tais como e-books interativos feitos em ePub3, e-books de realidade aumentada e book apps (LLIA), os quais permitem a utilização de diversas mídias e diferentes interações.

Os LLIA são criações híbridas multimodais e multissensoriais (incluem texto escrito, imagem, som, música, movimento, entre outros modos), que potencializam a interatividade, a criatividade e a motivação, e que são acessadas por meio de diferentes dispositivos digitais (CORRERO; REAL, 2014; SERAFINI; KACHORSKY; AGUILERA, 2015, 2016). Conforme Correro e Real (2014), as crianças podem atuar sobre a produção literária, o que Ihes proporciona "uma experiência de leitura mais exploratória e emocional, melhora a compreensão e o protagonismo e possibilita o aumento das habilidades interpretativas." (CORRERO; REAL, 2014, p. 227, tradução nossa). 
Pereira (2017) lembra que, enquanto nos livros impressos o texto verbal e as imagens se relacionam no espaço pouco mutável da página dupla (o conjunto formado pelas páginas par e ímpar justapostas, unidas pela dobra do livro), a superfície de organização nos LLIA possibilita a superposição de elementos em camadas e a expansão das dimensões do espaço representativo em todas as direções a partir de ações como deslizar a imagem pela área visível da tela.

A forma de transitar entre uma página/tela e outra dos LLIA também difere dos impressos. Os recursos de transição dizem respeito aos modos como o leitor/agenciador transita de uma tela para a outra do livro digital interativo (SERAFINI; KACHORSKY; AGUILERA, 2016). Além disso, o elemento fundamental que diferencia os LLIA dos e-books convencionais é a página interativa. De acordo com Leffa e Marzari (2012), a página interativa difere da página dupla impressa, e mesmo da página digital, por não ser um objeto estático, exposto ao olhar do leitor, tipicamente posicionado do lado externo. A página interativa consiste em evento que se instancia em reação a um gesto do participante, capturado por algum dispositivo de entrada (mouse, painel, microfone ou câmera), e que resulta em outro gesto, oriundo do objeto, dando algum tipo de resposta.

Tanto e-books em ePub3 quanto os LLIA podem ser chamados de enhanced e-books (livros digitais enriquecidos ou melhorados), quando para além de texto verbal, combinam áudio, imagem em movimento, enlaces hipertextuais, jogos e até ferramentas de participação em redes sociais da Internet. A principal finalidade do "enriquecimento" em livros digitais é favorecer a interatividade, no entanto, muitas vezes, são inseridos jogos, efeitos sonoros, elementos pop-up, animações, ativações por movimentação, toque e voz, função karaokê e interações que se sobressaem ao enredo da narrativa, ao ponto da criança se dedicar unicamente a estes conteúdos multimidiáticos (GARCÍA-RODRÍGUEZ; GÓMEZDÍAS, 2016).

É muito fácil encontrar, em diferentes níveis de interação dos leitores com LLIA, conexões com jogos digitais. Elas podem ser divididas em dois tipos. A primeira consiste na participação direta do leitor no próprio jogo, que é oferecido separadamente da narrativa literária. A segunda está relacionada à noção de gamificação, que deve ser entendida como o uso de elementos do design de jogos digitais em contextos externos ao dos games propriamente ditos, para motivar e aumentar a atividade e a atenção do leitor (ZAJĄC, 2013).

Kapp (2012) afirma que a gamificação consiste na utilização de elementos dos jogos digitais (mecânicas, estratégias, pensamentos) fora do seu contexto original, com a finalidade de motivar os sujeitos à ação, auxiliar na solução de problemas e promover aprendizagens. Fardo (2013) descreve a gamificação como um fenômeno emergente, derivado da popularização e da popularidade dos games, e de suas capacidades intrínsecas de influenciar as mais diversas áreas do conhecimento e da vida dos sujeitos. 
De acordo com Pereira (2017), os conhecimentos advindos desse fenômeno são empregados no funcionamento de jogos e histórias multimídias para crianças desde os CDROMs de gerações passadas e vem sendo cada vez mais explorados no desenvolvimento de livros aplicativos, aos quais são possibilitados movimentos interativos (pegar e soltar, pinçar, expandir, girar, entre outros) similares aos jogos digitais.

Em estudos anteriores, Yokota e Teale (2014), ao analisar algumas interações presentes nos LLIA, perceberam a integração de jogos no decorrer da narrativa ou ao final da história. Os jogos frequentemente encontrados nos livros analisados por esses pesquisadores foram quebra-cabeças, adivinhas e atividades para desenhar e colorir. Sargeant (2015), a partir de suas pesquisas, também atenta para o fato de que essa gamificação nos livros aplicativos normalmente se dá apenas pela inclusão de brincadeiras e quebra-cabeças, e não por meio de inserção de modelos formais de jogos. A autora explica que as brincadeiras são atividades exploratórias de livre circulação dentro de uma determinada estrutura, sendo bem menos estruturadas que os jogos, os quais constituem em sistemas baseados em regras que ligam o jogador aos resultados.

No tocante ao jogo digital, Cezarotto e Battaiola (2017) ressalvam que a sua qualidade de interface deverá ser avaliada por testes de usabilidade, em que se mensura o nível de facilidade e acessibilidade que a interface oferece para que o sujeito consiga atingir os seus objetivos com eficácia, eficiência e satisfação. Todavia, para avaliar interfaces de jogos é necessário considerar também o elemento entretenimento, ou seja, a diversão.

Torna-se extremamente relevante, portanto, a discussão das transformações que as tecnologias digitais provocam nas concepções do livro de literatura infantil, e como essas mudanças propiciam novas formas, tempos e espaços de leitura a partir dos elementos de gamificação, considerando o uso cada vez mais precoce de dispositivos móveis de interação por parte das crianças, aliada à incipiente produção de LLIA.

Na próxima seção, apresenta-se a descrição do percurso metodológico assumido por este estudo, com o intuito de detalhar o processo de delimitação dos dados da pesquisa.

\section{O percurso metodológico}

Trata-se de pesquisa qualitativa, que utiliza métodos de investigação de base interpretativista, pois busca a interpretação de fenômenos e a descrição de significados por meio de análise indutiva e visa à descrição, compreensão e explicação das relações entre o global e o local em determinado fenômeno e o respeito ao caráter interativo entre os objetivos buscados, suas orientações teóricas e seus dados empíricos (MINAYO, 2001). As pesquisas que focalizam os Letramentos, por sua preocupação com questões sociais e por 
seu interesse voltado para os usos reais das linguagens, têm adotado metodologias de caráter qualitativo-interpretativista (MOITA LOPES, 1996).

Delimitou-se como corpus de pesquisa três livros aplicativos do BolognaRagazzi Digital Award (Feira do Livro Infantil de Bolonha, Itália) no ano de 2016 - "Wuwu \& Co." (HELLE; SLOCINSKA, 2015), "Chomp" (NIEMANN, 2016) e "Goldilocks and Little Bear" (NOSY CROW, 2015) - e três do Prêmio Jabuti (Brasil) na categoria "Infantil Digital" nos anos de 2015, 2016 e 2017 - "A trilha" (ASSE, 2014), "Flicts" (ZIRALDO, 2014) e "Monstros do cinema" (MASSI; KONDO, 2016).

Para ambas as premiações, optou-se em selecionar obras do conjunto de finalistas, e não apenas as vencedoras, para que não houvesse restrições quanto aos sistemas operacionais e suportes/dispositivos utilizados, assim como, ampliação no tocante ao gênero elencado previamente.

A leitura dos textos contemporâneos exige tanto conhecimentos dos dispositivos móveis de interação e dos mecanismos de navegação pelos ambientes hipermidiáticos, quanto habilidades de busca e compreensão das informações almejadas. Nesses procedimentos, o leitor/agenciador lida com percursos e possibilidades que demandam estratégias de escolhas frente ao encontro com uma profusão de tipografias, imagens, animações, vídeos, sons, hiperlinks, leiautes e formatos diversos.

Apresenta-se, na próxima seção, uma amostra da ocorrência de agenciamentos e interações multimodais (KRESS; VAN LEEUWEN, 1996; KRESS, 2010; COPE; KALANTZIS, 2010) nos LLIA selecionados - associada aos elementos narrativos e estruturais - que mobilizam práticas multiletradas de leitura envolvendo elementos de gamificação.

\section{Apresentação e discussão dos resultados}

As seis obras analisadas se constituem em transformações de livros de literatura infantil para inclusão de recursos digitais, das quais "Wuwu \& Co.", "Chomp", "Goldilocks and Little Bear" e "A trilha" são criações propriamente digitais, enquanto "Monstros do cinema" e "Flicts" têm contraponto em obra análoga impressa.

"Wuwu \& Co." é o único dos LLIA analisados que contempla adição de recursos interativos que genuinamente extrapolam as narrativas, por meio de experiências gamificadas, ou seja, a utilização de mecânicas, estratégias e pensamentos típicos dos jogos digitais, fora do seu contexto original, com a intenção de motivar os leitores à ação, auxiliando-os na solução dos desafios propostos pelas personagens nas narrativas (textos verbais escritos). 
Nos exemplos dos LLIA selecionados, mostra-se que o leitor, em alguns momentos, realiza práticas de leitura que envolve gamificação, enquanto participa de jogos de forma independente em outras situações.

Os elementos de gamificação presentes em "Wuwu \& Co.", mesmo estando na linha tênue entre os quebra-cabeças e as brincadeiras, preserva a lógica da busca por resultados inerente aos jogos no decorrer da narrativa ou ao final de cada bloco da história, potencializando a produção de sentidos por parte do leitor. A própria configuração do sistema de navegação usado pelo LLIA tem as propriedades de um jogo, no qual a criança enfrenta o primeiro desafio, que é identificar quais soluções de interface são usadas para operar o aplicativo.

A Figura 1 apresenta um momento da história da personagem Wuwu em que o leitor deve ajudá-la a afugentar o tubarão que não a deixa pescar no mar. Para tanto, é necessário dar toques sequenciais com o dedo indicador no alvo que surge na tela, assim como ocorre nos tradicionais jogos de tiro. Após a sessão de tiros, com direto à sonorização das balas atingindo o tubarão, escuta-se o seu grito de dor e a tela fica avermelhada. O tubarão é afugentado com sucesso, para a alegria de Wuwu, que poderá realizar sua pescaria novamente. Considerando que a obra é dirigida para crianças acima de 6 anos, lança-se o questionamento sobre a veracidade desta cena, que de certa forma, simula ou incita a violência contra um animal marinho, mesmo que seja, nas palavras de Wuwu, "um tubarão estúpido".

Figura 1 - Elementos de gamificação na história de Wuwu, em "Wuwu \& Co."

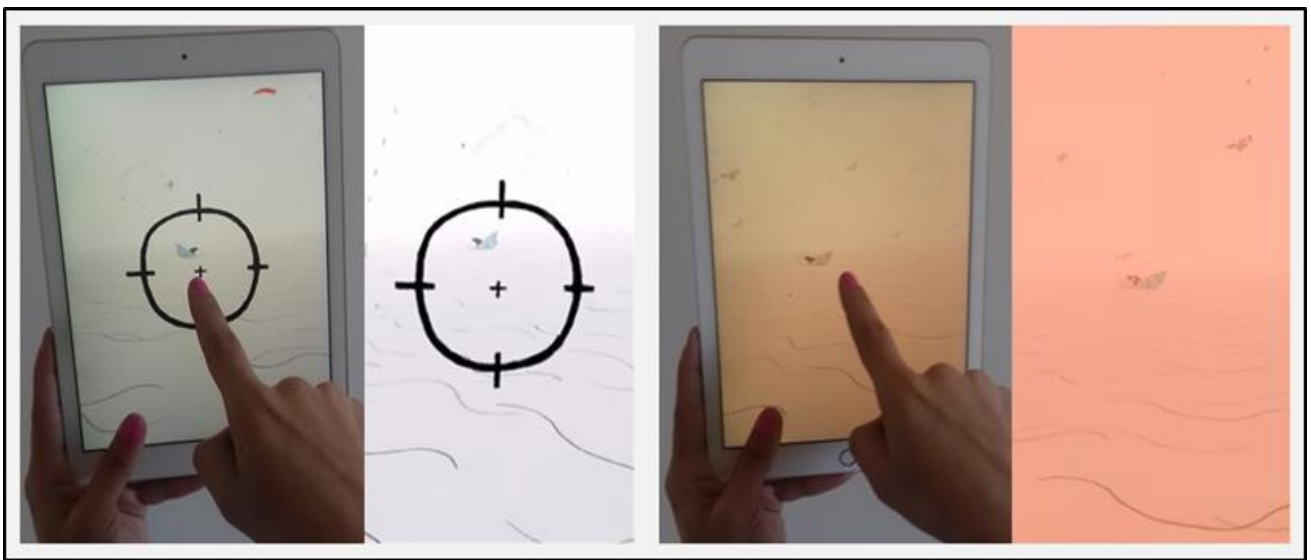

Fonte: Helle e Slocinska (2015)

Já na história de Pruney (Figura 2), mais especificamente em seu final, há a presença de um "jogo" (uma brincadeira) em que o leitor/agenciador empurra o trenó montanha abaixo por meio do toque e do deslizar do dedo indicador, promovendo divertimento mútuo, pois se ouve as personagens gritando "uíiiiiiiiiiiiiii". Esse "jogo" está disponível logo após o leitor ajudar o troll a encontrar a sua caixa de fósforos, a qual estava em posse do 
esquilo, por meio de toques nos palitos jogados sobre o chão encoberto de neve. Percebe-se que as ações de tocar e clicar em objetos da tela ou deslizá-los, selecionar e pressionar itens animados, entre outras, já se constituem em elementos de gamificação.

Figura 2 - Elementos de gamificação na história de Pruney, em "Wuwu \& Co."

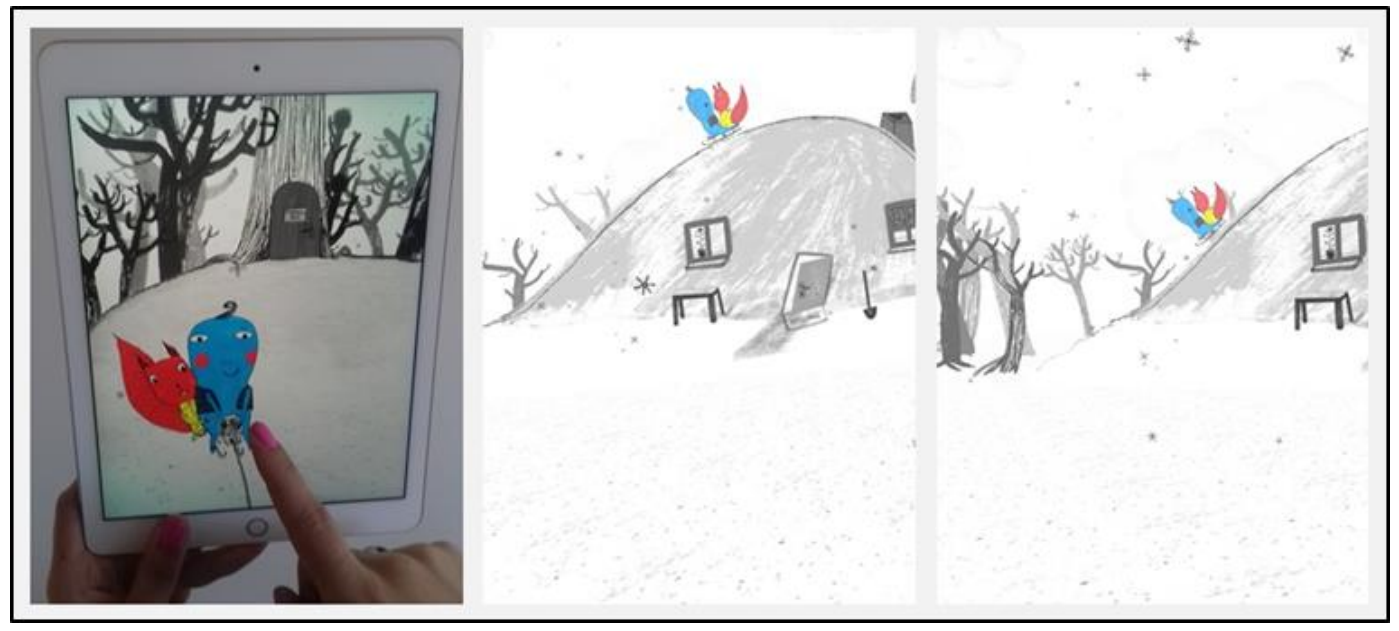

Fonte: Helle e Slocinska (2015)

"Chomp" é um LLIA que até poderia ser categorizado simplesmente como "aplicativo para crianças" por possuir narrativas viso-sonoras curtas que não possuem correlação entre si, muitas vezes, se assemelhando a um jogo digital. Um dos momentos em que isso fica manifesto é a cena do "pingue-pongue" (Figura 3), em que o leitor/agenciador posiciona seu rosto no círculo que representa a bolinha, e, por meio de toques na raquete, simula a ação do jogo real.

Figura 3 - Elementos de gamificação em "Chomp"

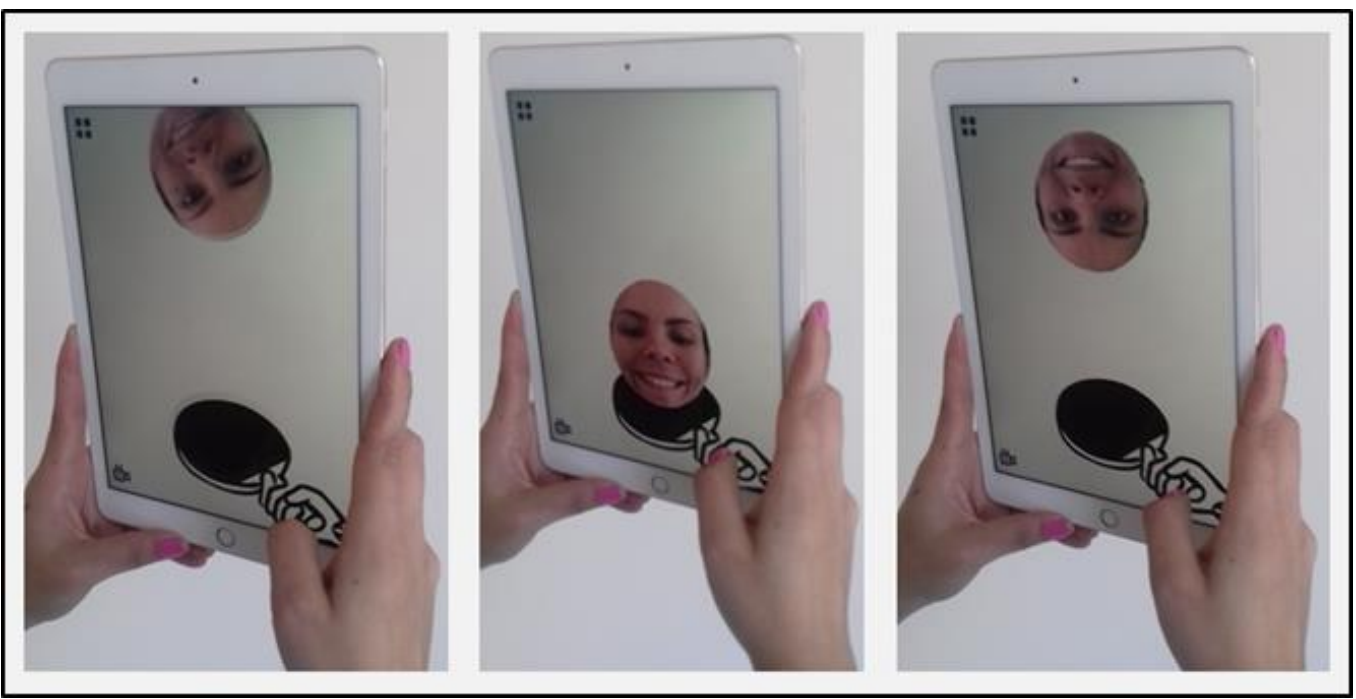

Fonte: Niemann (2016) 
O LLIA "Goldilocks and Little Bear" é repleto de elementos de gamificação, que se apresentam ao longo das narrativas a partir dos recursos interativos de agenciamento disponíveis ao leitor. Na Figura 4, por exemplo, são mostrados dois momentos em que o leitor pode brincar com as personagens: no primeiro, faz-se Goldilocks pular nas camas dos três ursos por meio da movimentação (para cima e para baixo) do dedo indicador; no segundo, veste-se Little Bear com as roupas e os acessórios presentes nos três guardaroupas do quarto dos humanos.

Figura 4 - Elementos de gamificação em "Goldilocks and Little Bear"

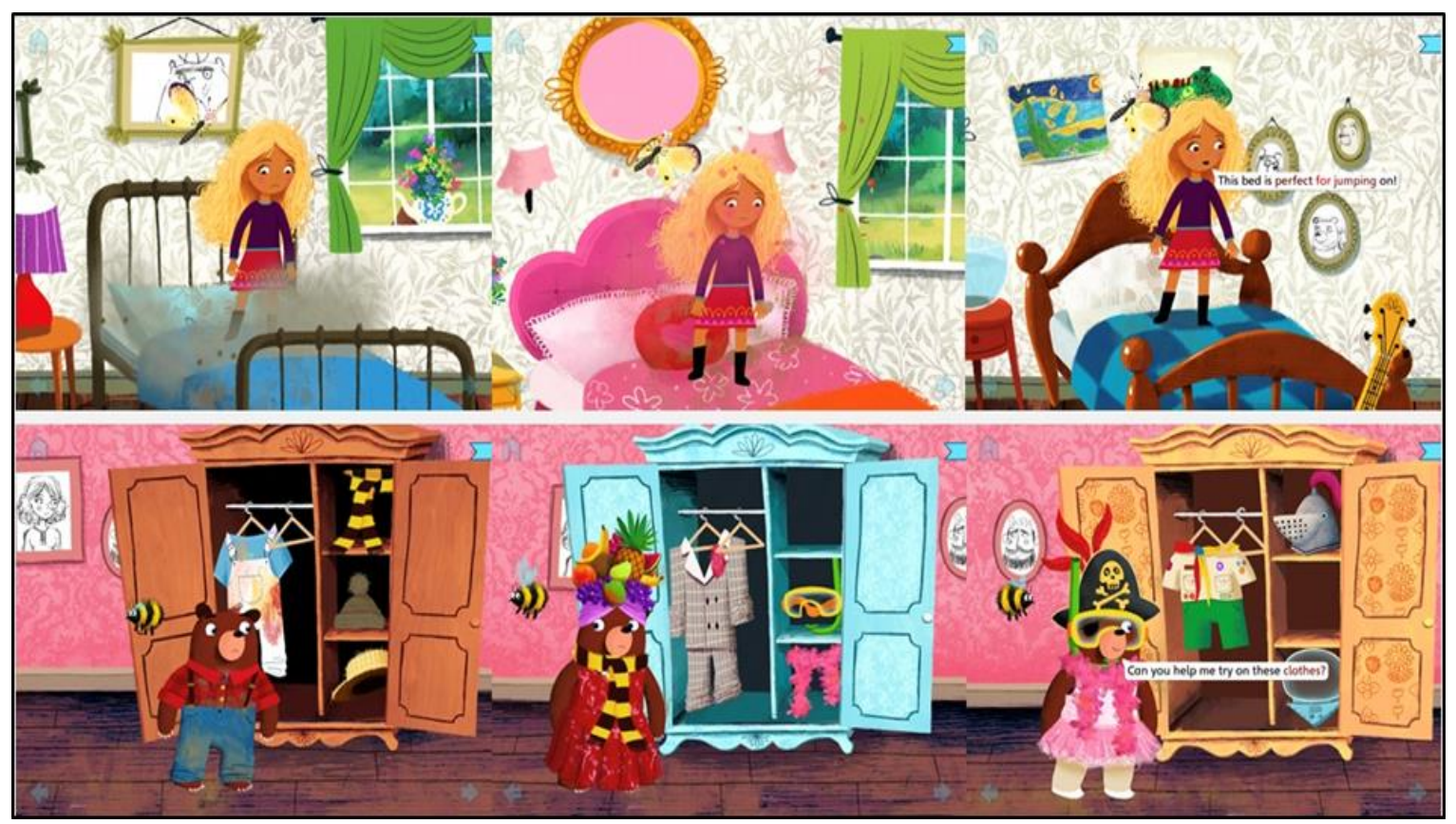

Fonte: Nosy Crow (2015)

Em "Flicts", o leitor encontra elementos de gamificação durante sua experiência de leitura e também jogos digitais disponíveis no menu inicial "Outros Apps". A Figura 5 retrata duas passagens da narrativa que incluem possibilidades de interação que se assemelham a brincadeiras, como desenhar ou escrever no fundo de apresentação da cor Flicts (ocre) e girar o espectro de cores por meio de movimentos circulares. A Figura 6 exibe as telas iniciais dos dois jogos - Dominó e Jogo da memória - disponíveis para serem baixados na loja virtual da mesma produtora de "Flicts", habilitados com a inserção de uma senha numérica, mediante a "autorização" de um adulto. 
Figura 5 - Elementos de gamificação em "Flicts"

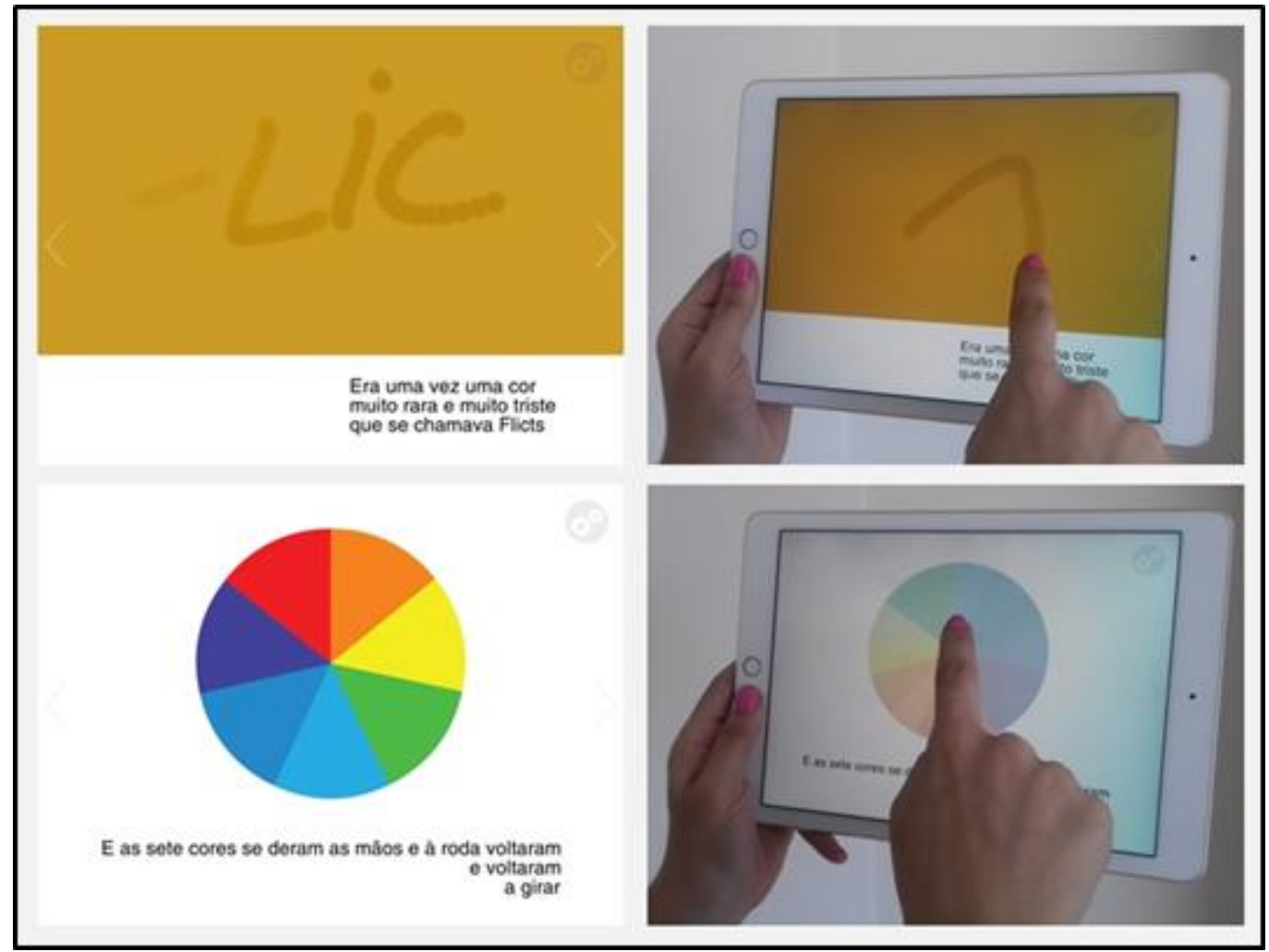

Fonte: Ziraldo (2014)

Figura 6 - Jogos digitais extras em "Flicts"

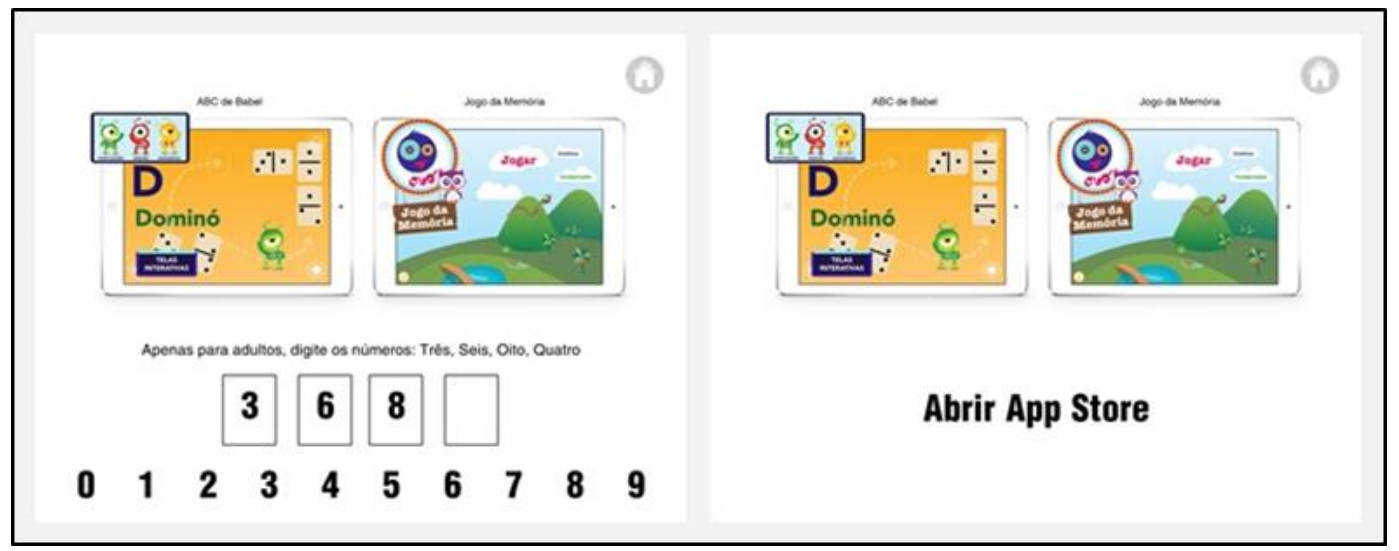

Fonte: Ziraldo (2014)

Em "A trilha", o leitor se depara com desafios incorporados ao enredo da narrativa que representam ou se assemelham a brincadeiras da vida real, por meio das experiências cinéticas e sonoras, como os exemplos mostrados na Figura 7: o leitor não consegue avançar na leitura da história enquanto não tocar na ponta do vestido vermelho da menina; o leitor deve girar a roda de ciranda pela movimentação circular do dedo indicador. 
Figura 7 - Elementos de gamificação em "A trilha"

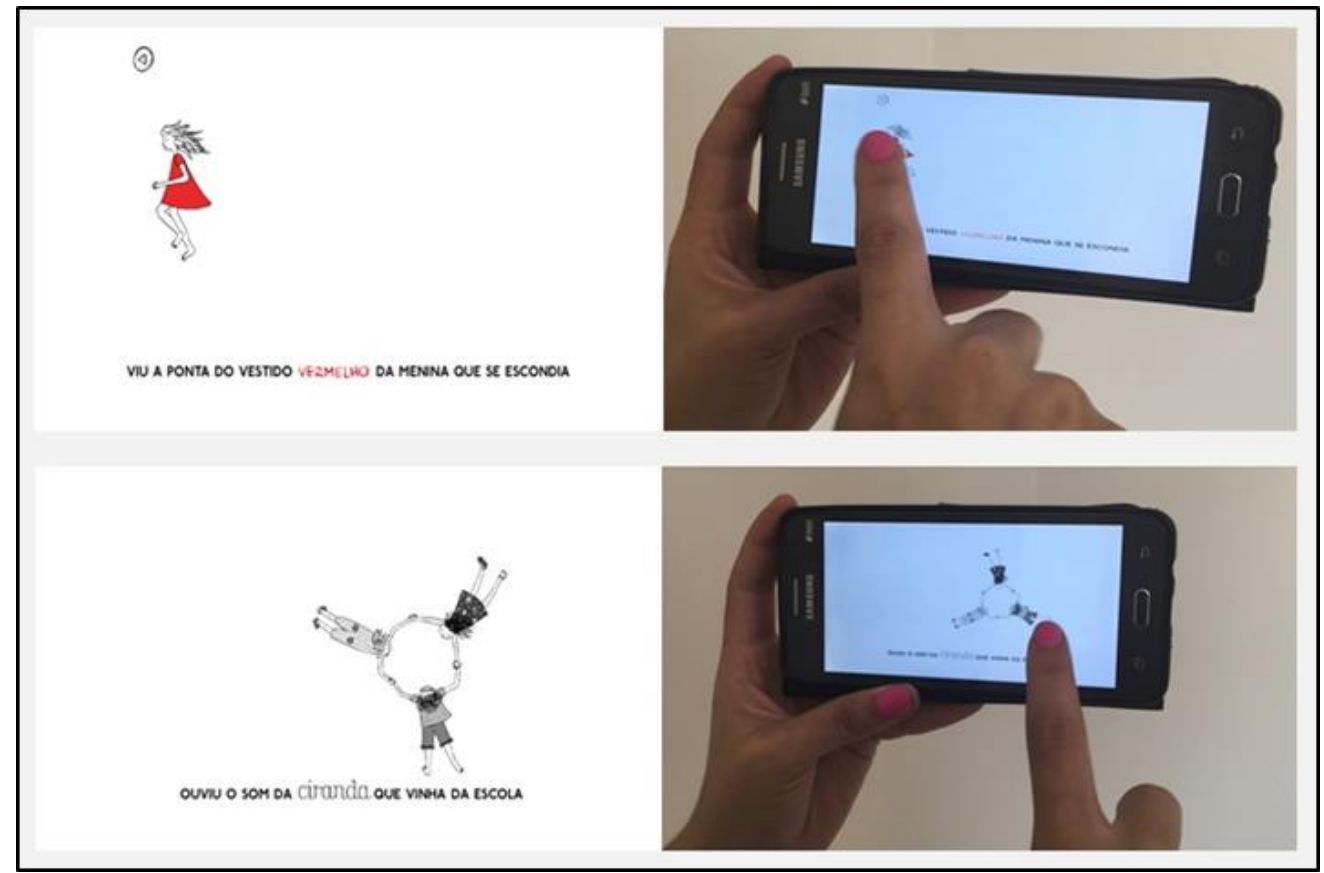

Fonte: Asse (2014)

Na obra "Monstros do cinema" (Figura 8), os personagens mais assustadores do cinema foram "fatiados" em três pedaços: cabeça, tronco e membros inferiores. Após embaralhar as partes, o leitor/agenciador pode escolhê-las para montar o seu próprio monstrengo. Ou ainda, por meio do acionamento de uma alavanca, o aplicativo escolhe randomicamente cada uma das partes.

Figura 8 - Elementos de gamificação em "Monstros do cinema"

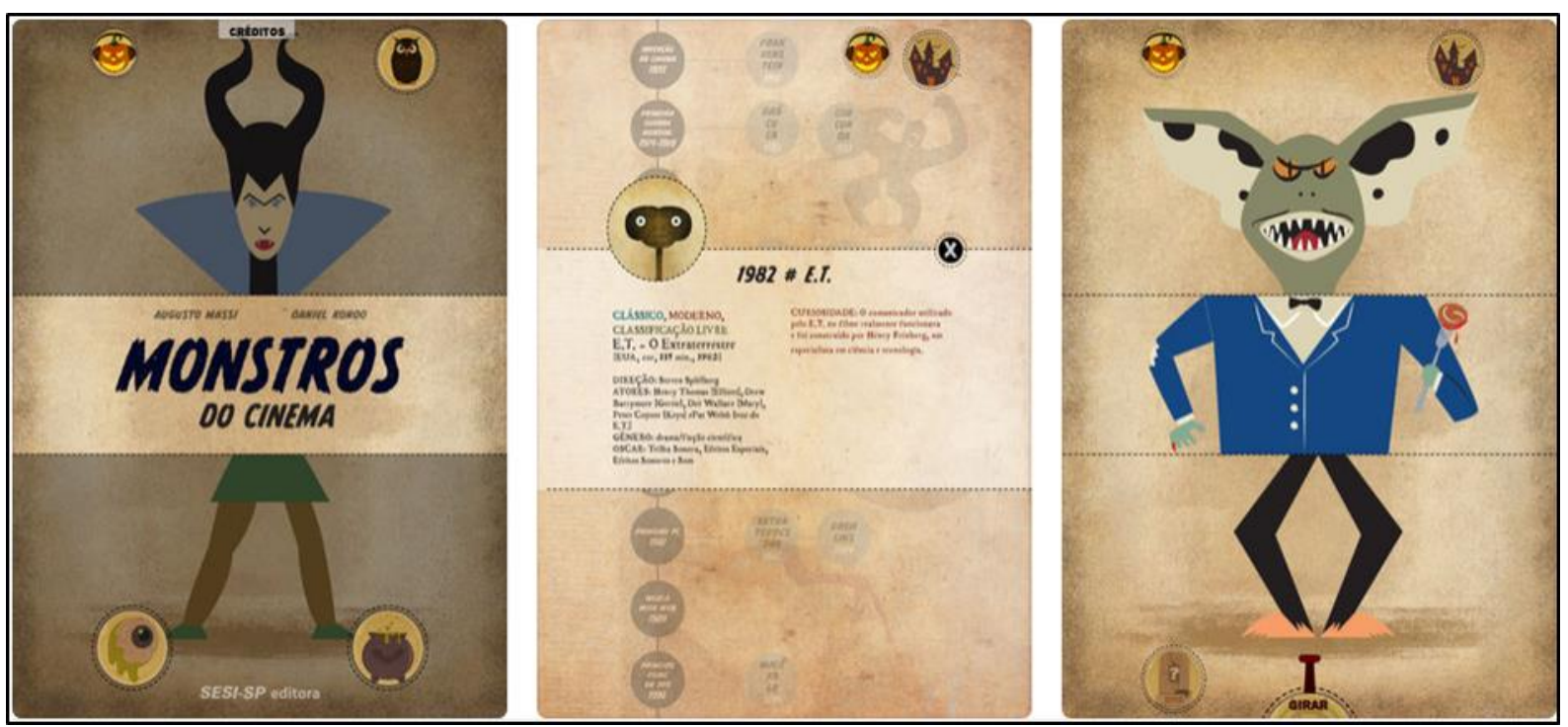

Fonte: Massi e Kondo (2016) 
Por meio de excertos imagéticos, apresentam-se, na sequência, as interações multimodais - visual, por voz ou som, háptica (tátil/gestual), por movimento (do aparelho) -, proporcionadas pelos LLIA que compõem o corpus da pesquisa, as quais possibilitam ao leitor tornar-se um agenciador de sentidos e não um mero receptor de conteúdos.

A visualidade é o principal meio de interação na obra "Chomp", em que o maior desafio reside na exploração de novas, diferenciadas e criativas formas de narrar e de se expressar diante das demandas dos textos imagéticos, justamente em função da ausência da linguagem escrita e pela introdução da experiência estesiológica. Na Figura 9, são exibidas imagens animadas de um maestro, potencializadas por meio de trilha sonora específica, que se movem por meio da ação do leitor, o qual insere as suas expressões faciais e movimentação do rosto conforme o seu entendimento da proposta da narrativa visual de uma regência de orquestra.

Figura 9 - Interação visual em "Chomp"

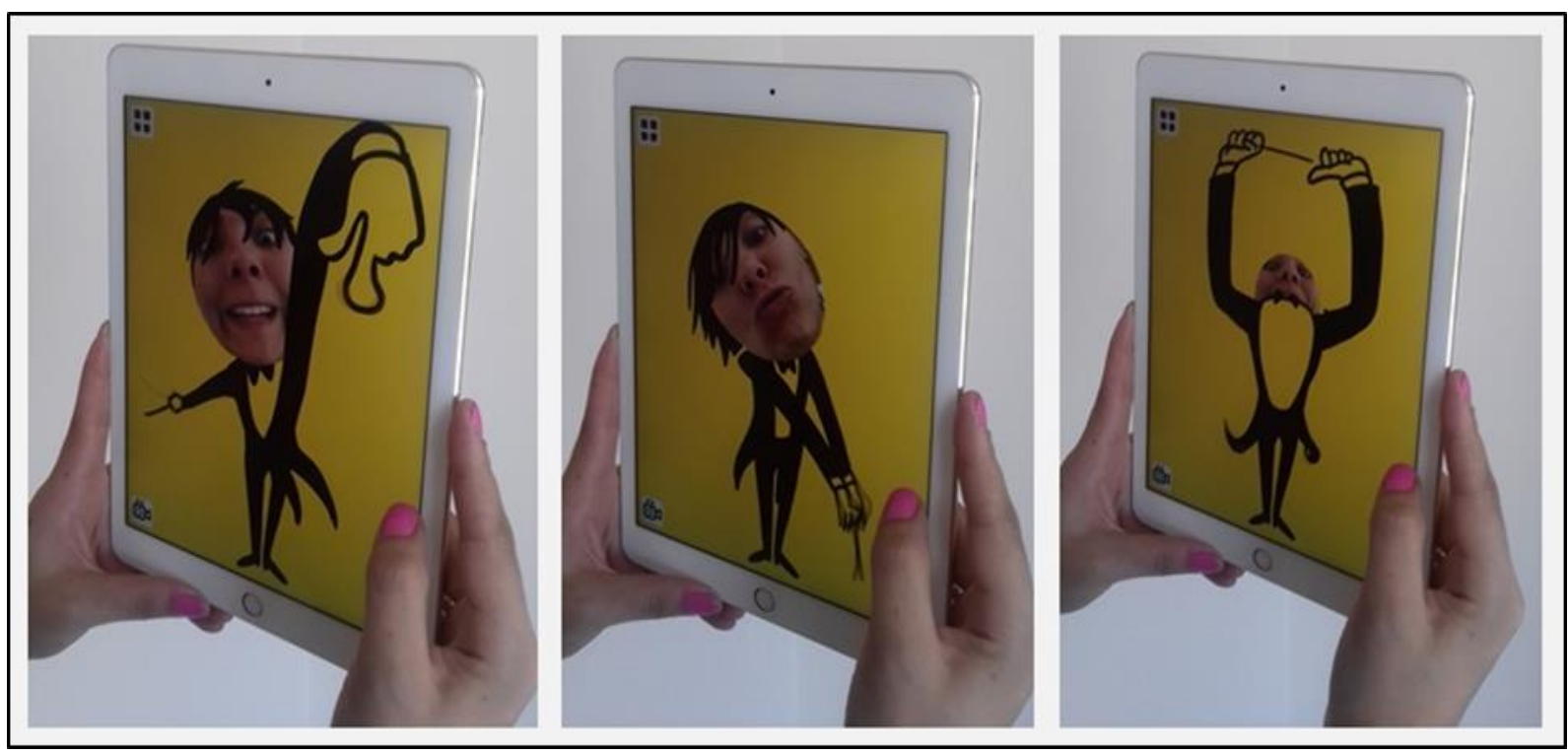

Fonte: Niemann (2016)

Das obras analisadas, "Wuwu \& Co." destaca-se pelo uso de microfone do dispositivo móvel de interação para realizar a gravação de voz e sons, os quais são utilizados para a composição de algum detalhe da narrativa. A incorporação de voz é possível apenas no cenário da personagem Everett, em que o leitor/agenciador precisa gritar ou falar alto ao microfone para acordar os Everetts no alto de uma árvore, para que consigam se refugiar do frio rigoroso que se aproxima. Assim que são acordados, os três grupos de Everetts passam a repetir aquilo que foi pronunciado pelo agenciador (Figura 10). 
Figura 10 - Interação por voz em "Wuwu \& Co."

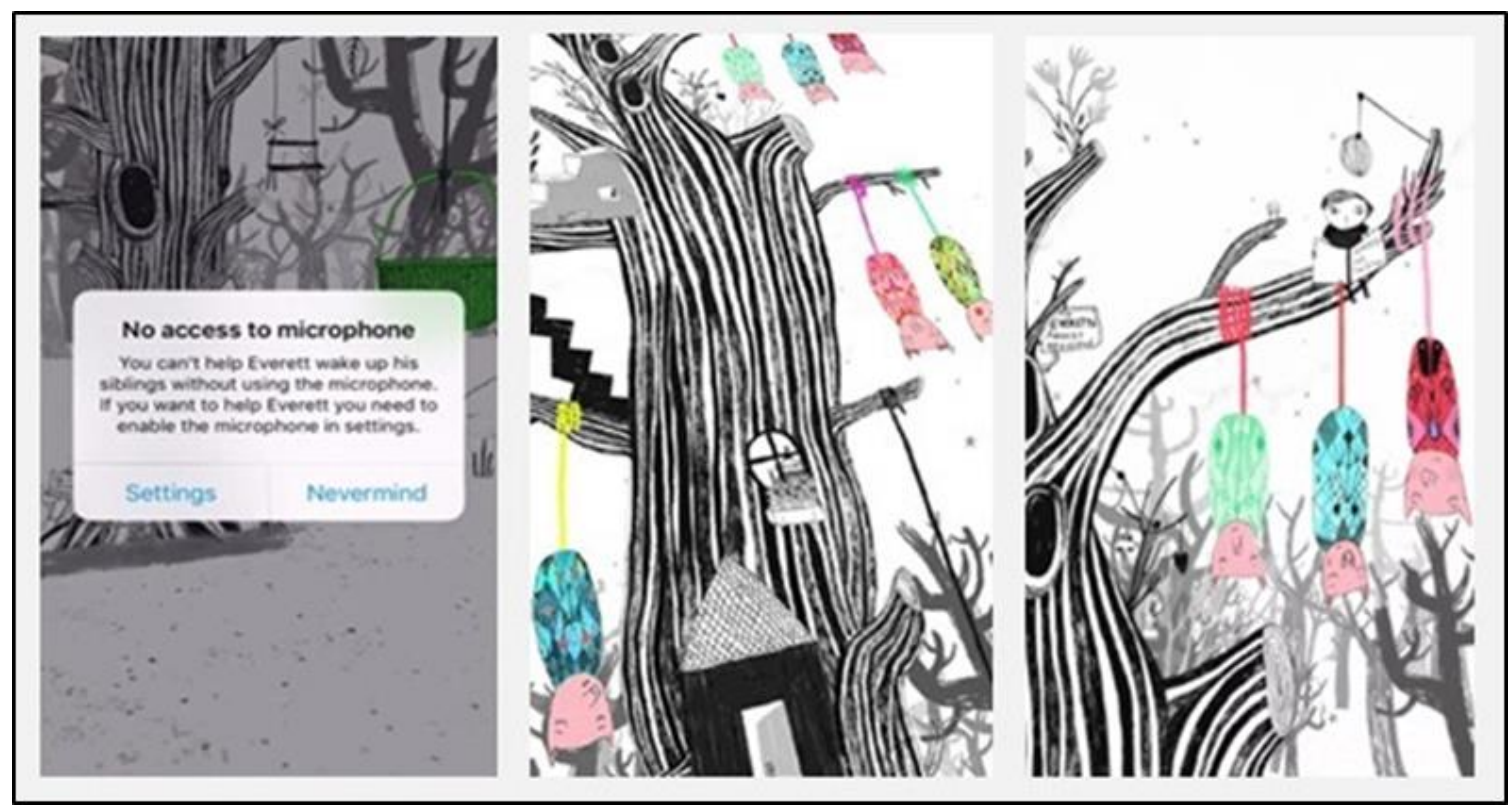

Fonte: Helle e Slocinska (2015)

Dentre os recursos de interatividade observados em "Goldilocks and Little Bear" e "A trilha", por exemplo, destacam-se os desafios táteis e gestuais inseridos na experiência da narrativa, fazendo com que a leitura nesses LLIA possa ser englobada na esfera da gamificação, uma vez que são observadas performances corporais, mecânicas e estratégias peculiares aos jogos digitais, tais como usar menus, aplicar comandos (mover, clicar, deslizar, selecionar, etc.), identificar e reconhecer códigos visuais, passar os olhos estrategicamente pelas páginas/telas, cumprir tarefas preestabelecidas e vencer/ultrapassar barreiras ou fases de maneira progressiva. Nesse sentido, constata-se que a interface multimodal do LLIA possibilita as sensações de presença e imersão ao leitor/agenciador na medida em que o corpo deste responde ou não a comandos programados, executa ou não as atividades requeridas para avançar no enredo da história contada.

Portanto, a leitura nesses LLIA, ao passo em que compreende algumas estratégias análogas à leitura em ambientes tradicionais, como visualizar, analisar, inferir, entre outras, expande - mesmo que brevemente - a narrativa literária para fora do ambiente projetado na tela.

A Figura 11 exibe dois momentos em que o leitor realiza agenciamento/atuação cinestésica na experimentação da narrativa em "A trilha": na primeira página/tela, o personagem Martim é apresentado ao leitor acompanhado do enunciado "Martim é um menino FORTE". Para ter acesso à próxima página, o leitor é convidado por Martim para ajudá-lo a colocar cada uma das letras da palavra forte (em caixa alta e destaque tipográfico) sob seus braços, colaborando para o entendimento da mensagem; em outro momento da 
narrativa, em que Martim interrompe o passeio de bicicleta para pisar na lama macia, o leitor é instigado a brincar de fazer pegadas por meio de simulação de diferentes patas/pés, acionados pelo toque na tela.

Figura 11 - Interação háptica em "A trilha"

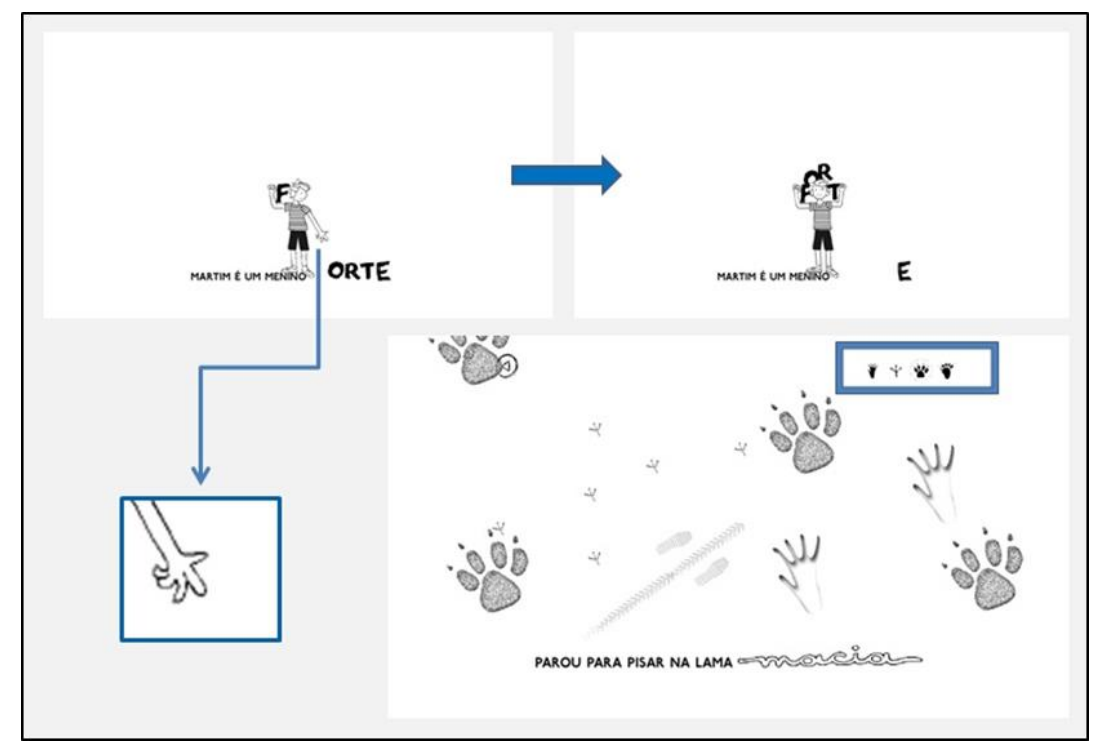

Fonte: Asse (2014)

A Figura 12 mostra duas imagens do momento em que Goldilocks foge da casa de Little Bear e é perseguida pelos pais do ursinho pela floresta. Enquanto corre, a menina pede ajuda para saltar as toras que trancam o caminho. O leitor/agenciador pode tocar nelas, simulando o movimento de pulo com seus dedos. Se o leitor não realizar essa ação, Goldilocks cambaleia após a colisão com os grandes troncos de madeira, reclamando que eles dificultam muito a corrida e se perguntando que não se lembra deles por ali anteriormente.

Figura 12 - Interação háptica em "Goldilocks and Little Bear"

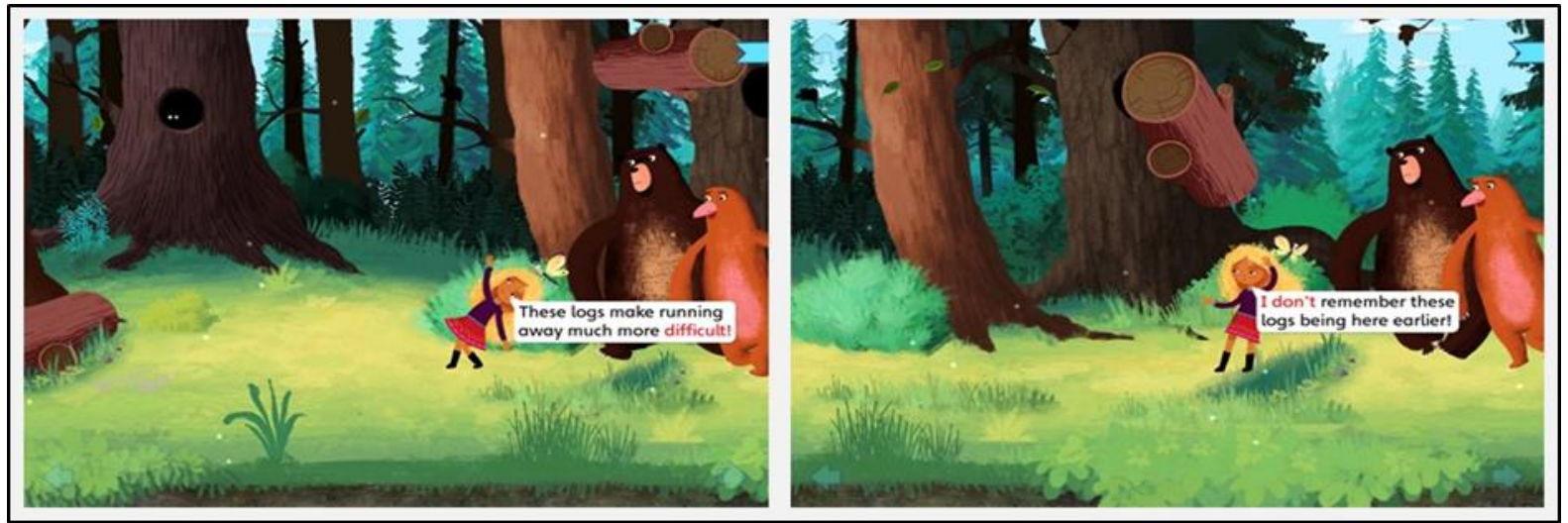

Fonte: Nosy Crow (2015) 
Dentre os seis LLIA que compõem o corpus de pesquisa, apenas "Wuwu \& Co." e "Goldilocks and Little Bear" contemplam recursos de interação por movimento do dispositivo móvel.

Com a presença de realidade aumentada e ambientes virtuais imersivos, "Wuwu \& Co." utiliza recursos de giroscópio (visão 360), acelerômetro, câmera e microfone, aplicando-os aos desafios propostos. Os recursos de giroscópio e acelerômetro constituem em diferenciais dessa obra, pois possibilitam ao leitor/agenciador, quando solicitado, inclinar, chacoalhar, mudar a posição vertical/horizontal e até virar o dispositivo de cabeça para baixo.

Neste LLIA, na cena em que a personagem Thit Maya solicita auxílio para derrubar as pinhas de um pinheiro para fazer uma sopa para ela e seus amigos, por exemplo, o leitor/agenciador deve movimentar o dispositivo rapidamente de forma a derrubá-las, como se estivesse chacoalhando a árvore (Figura 13). Verificou-se que as orientações sobre a maneira como o leitor/agenciador deve proceder para realizar esse desafio também são evidenciadas por meio de texto verbal escrito, em forma de lembrete ao final da narrativa: "Can you help Thit Maya and her friends shake the pine tree? Remember what she said: First the snow has to be shaken off, and then the pinecones have to be shaken to the ground." ["Você pode ajudar Thit Maya e seus amigos a agitar o pinheiro? Lembre-se do que ela disse: primeiro a neve tem que ser sacudida, e então as pinhas têm que ser sacudidas até o chão."].

Figura 13 - Movimentação do iPad na história de Thit Maya, em "Wuwu \& Co."

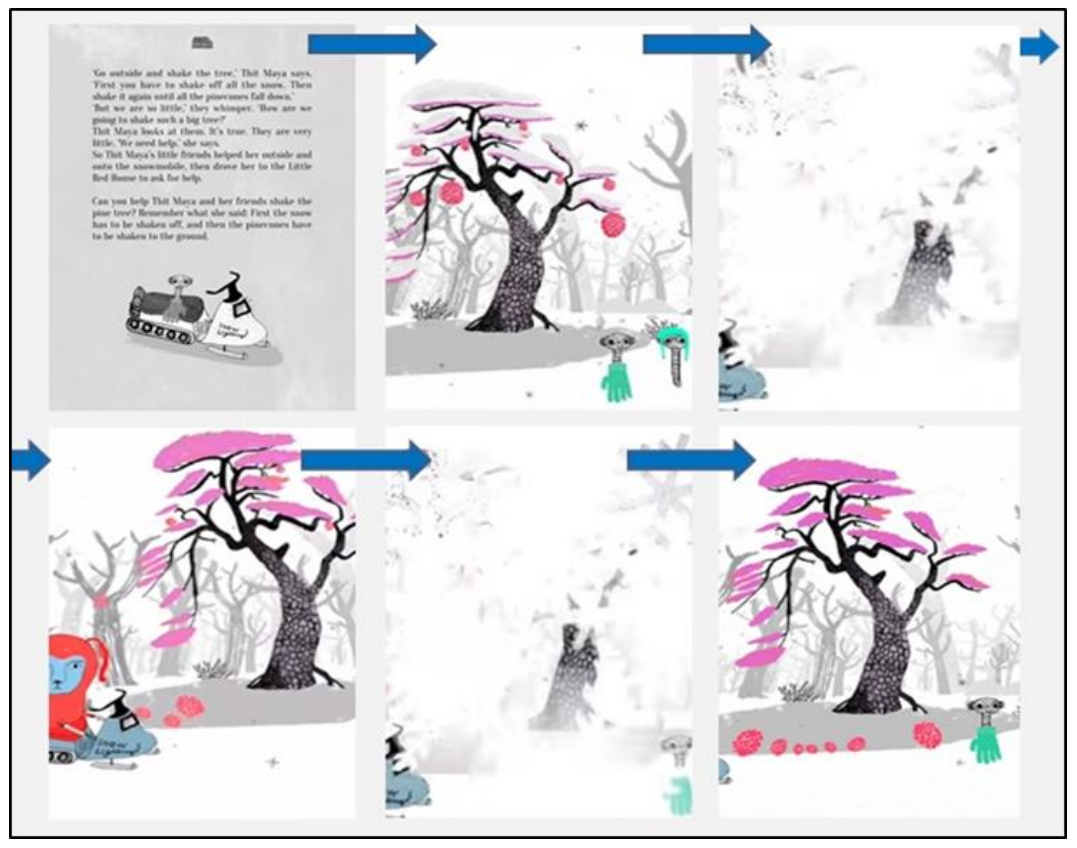

Fonte: Helle e Slocinska (2015) 
Em determinados momentos de "Goldilocks and Little Bear", é possível ao leitor/agenciador transitar entre a história da menina e a do pequeno urso por meio da mudança da posição do dispositivo (giro de 180ㅜ, na vertical, simulando o movimento de um volante de carro) para seguir, conjuntamente, as duas narrativas. Conforme mostra a Figura 14, o giro do aparelho pode ser realizado no momento em que surge na tela, os quadros com os rostos das personagens, adornados por setas arredondadas concêntricas.

Figura 14 - Interação por movimento do aparelho, em "Goldilocks and Little Bear"

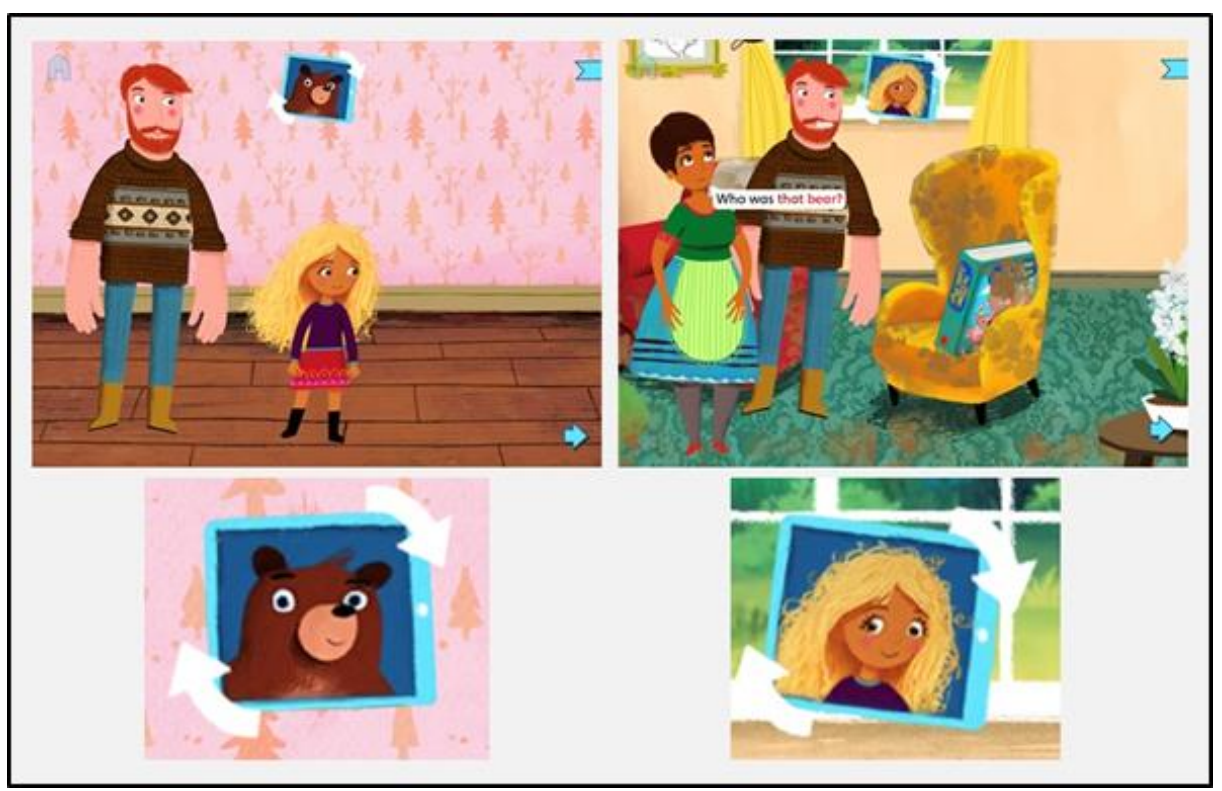

Fonte: Nosy Crow (2015)

Na cena em que Goldilocks senta-se na cadeira de Little Bear para experimentá-la, o leitor/agenciador pode realizar movimentos pendulares no aparelho para acionar o balanço. Quanto mais rápido o aparelho é movimentado, mais intenso será o balanço da cadeira, que, inevitavelmente, se despedaça, conforme exposto na Figura 15.

Figura 15 - Movimentação do iPad na história de "Goldilocks"

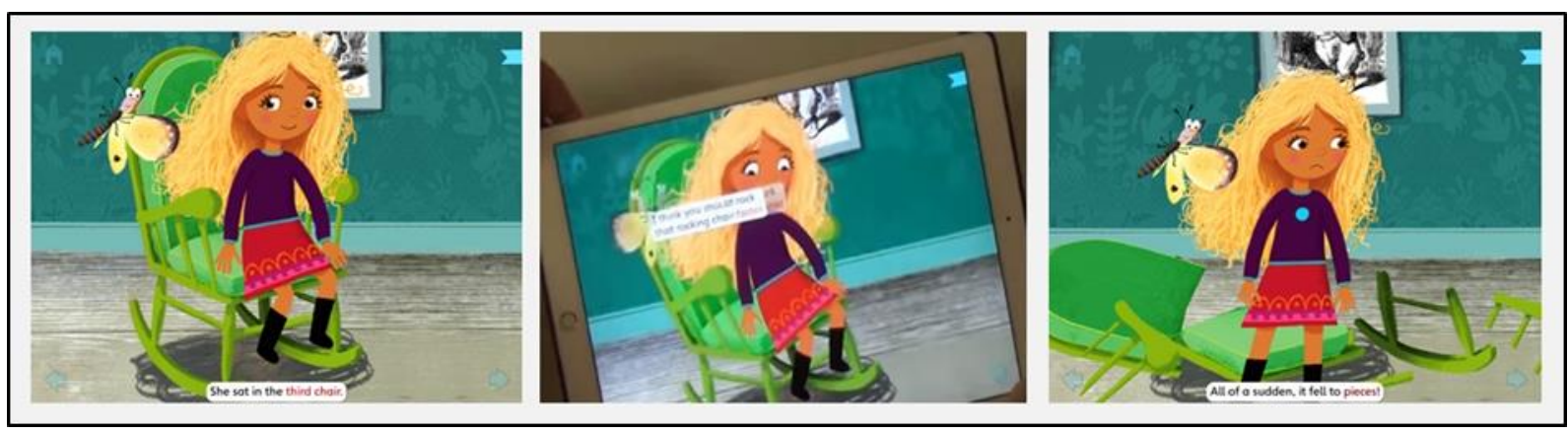

Fonte: Nosy Crow (2015) 
Em síntese, as obras "Wuwu \& Co.", "Goldilocks and Little Bear" e "A trilha" podem ser consideradas narrativas verdadeiramente interativas, pois se utilizam dos recursos sonoros, cinéticos e de gamificação como potencializadores para a compreensão do enredo narrativo, e não como meros recursos adicionais.

\section{Considerações finais}

A realização desta pesquisa possibilitou a percepção e análise dos elementos de gamificação em Livros Literários Infantis digitais interativos em formato de Aplicativos (LLIA), assim como, das práticas multiletradas acionadas na formação de leitores na infância.

Os LLIA escolhidos para compor o corpus de pesquisa possibilitam ao leitor/agenciador interagir ludicamente entre diversos recursos que mesclam o texto literário com elementos multissemióticos. A persuasão ao público infantil ocorre por meio da inter-relação entre leitura, agenciamento, criação, composição e os recursos que se assemelham aos utilizados pelos jogos eletrônicos.

No tocante à gamificação, entende-se que esta consiste em aplicação cuidadosa do pensamento dos jogos para encorajar aprendizagens, utilizando os mecanismos dos games que sejam percebidos pelo sujeito como desafiadores e fruitivos, com vistas à potencialização do engajamento do indivíduo com o ambiente em que está inserido.

Identificou-se que na relação entre as narrativas dos LLIA e os elementos de gamificação, estes contribuem para deixar os enredos mais emocionantes, pois os roteiros das histórias contemplam níveis progressivos, desafios, missões, busca por recompensas e retroalimentações, que possibilitam maior integração dos conteúdos com o imaginário do leitor, oportunizando que este leia em seu próprio ritmo. Portanto, os LLIA que utilizam estrategicamente os elementos de gamificação em sua composição, possuem tramas mais interativas e performativas.

Observou-se que na medida em que os sujeitos leem/agenciam, também são interpelados sobre questões relativas à sua corporeidade. Eles não permanecem inertes ao contato com o LLIA, visto que sua(s) leitura(s) geram experiências estesiológicas ímpares. 0 leitor lida com percursos e possibilidades que demandam estratégias de escolhas frente a uma profusão de tipografias, imagens, animações, vídeos, sons, hiperlinks, leiautes e formatos diversos. Manifestadas na corporeidade, a apropriação, a ampliação, a vivência e a transformação dessas diferentes linguagens oportunizam a significação e a ressignificação do(s) texto(s) e do leitor.

A leitura hoje demanda ação humana multissemiótica, em que a inovação e a criatividade passam a ser do domínio do cotidiano de sujeitos leitores em processo de 
transformação. O itinerário infantil das leituras, iniciado na primeira infância, amplia-se à medida que as crianças crescem, o que não significa que elas tenham que esperar a chegada a um determinado momento de sua formação para desfrutar da experiência literária em telas digitais interativas.

\section{Referências}

ASSE, R. A trilha. São Paulo: Editora Peirópolis, 2014. Book app.

CEZAROTTO, M. A.; BATTAIOLA, A. L. Avaliação de jogabilidade em jogos para crianças com discalculia: proposta de heurísticas. In: CONGRESSO INTERNACIONAL DE ERGONOMIA E USABILIDADE DE INTERFACES HUMANO TECNOLÓGICA, 16., 2017, Florianópolis. Anais... Florianópolis: Universidade Federal de Santa Catarina, 2017. https://doi.org/10.5151/16ergodesign-0004

COPE, B.; KALANTZIS, M. New media, new learning. In: COLE, D. R.; PULEN, D. L. (Ed.). Multiliteracies in motion: current theory and practice. New York: Routledge, 2010. p. 87-104.

CORRERO, C.; REAL, N. Panorámica de la literatura digital para la educación infantil. Textura, Canoas, n. 32, p. 224-244, set./dez. 2014.

COSSON, R. Círculos de leitura e letramento literário. São Paulo: Contexto, 2014.

FARDO, M. L. A gamificação aplicada em ambientes de aprendizagem. Renote - Revista Novas Tecnologias na Educação, Porto Alegre, v. 11, n. 1, p. 1-9, jan./jul. 2013. https://doi.org/10.22456/1679-1916.41629

GARCÍA-RODRÍGUEZ, A.; GÓMEZ-DÍAS, R. Lectura digital infantil: dispositivos, aplicaciones y contenidos. Barcelona: Editorial UOC, 2016.

HAYLES, N. K. Literatura eletrônica: novos horizontes para o literário. São Paulo: Global; Passo Fundo: UPF Editora, 2009.

HELLE, M. P.; SLOCINSKA, K. Wuwu \& Co.: a magical picture book. Copenhague: Step in Books, 2015. Book app.

JOUVE, V. A leitura. São Paulo: Editora UNESP, 2002.

KAPP, K. M. The gamification of learning and instruction: game-based methods and strategies for training and education. San Francisco: Pfeiffer, 2012. https://doi.org/10.1145/2207270.2211316

KIRCHOF, E. R. O desaparecimento do autor nas tramas da literatura digital: uma reflexão foucaultiana. Signo, Santa Cruz do Sul, v. 34, n. 56, p. 47-63, jan./jun. 2009.

KRESS, G. R. Multimodality: a social semiotic approach to contemporary communication. New York; London: Routledge, 2010. https://doi.org/10.4324/9780203970034

KRESS, G. R.; VAN LEEUWEN, T. Reading images: the grammar of visual design. New York: Routledge, 1996.

LEFFA, V. J.; MARZARI, G. Q. Design da página interativa na perspectiva da semiótica social. 
Linguagem em (Dis)curso, Tubarão, v. 12, n. 2, p. 495-516, maio/ago. 2012. https://doi.org/10.1590/S1518-76322012000200006

MASSI, A.; KONDO, D. Monstros do cinema. São Paulo: Editora SESI-SP, 2016. Book app.

MINAYO, M. C. S. Ciência, técnica e arte: o desafio da pesquisa social. In: MINAYO, M. C. S. (Org.). Pesquisa social: teoria, método e criatividade. 19. ed. Petrópolis: Vozes, 2001. p. 9-30.

MOITA LOPES, L. P. Oficina de linguística aplicada: a natureza social e educacional dos processos de ensino/aprendizagem de línguas. Campinas: Mercado de Letras, 1996.

NIEMANN, C. Chomp. [S.I.]: Fox \& Sheep, 2016. Book app.

NOSY CROW. Goldilocks and Little Bear. Londres: Nosy Crow, 2015. Book app.

PEREIRA, T. E. Storytelling em e-picturebooks e implicações cognitivas. 2017. $129 \mathrm{f}$. Dissertação (Mestrado em Artes, Cultura e Linguagens) - Universidade Federal de Juiz de Fora, Juiz de Fora, 2017.

ROJO, R. Letramentos múltiplos, escola e inclusão social. São Paulo: Parábola Editorial, 2009.

SERAFINI, F.; KACHORSKY, D.; AGUILERA, E. Picturebooks 2.0: transmedial features across narrative platforms. Journal of Children's Literature, v. 41, n. 2, p. 16-24, mar./jun. 2015.

SERAFINI, F.; KACHORSKY, D.; AGUILERA, E. Picture books in the digital age. The Reading Teacher, v. 69, n. 5, p. 509-512, mar./abr. 2016. https://doi.org/10.1002/trtr.1452

SARGEANT, B. What is an ebook? What is a Book App? And why should we care? An analysis of contemporary digital picture books. Children's Literature in Education, v. 46, n. 4, p. 454466, dez. 2015. https://doi.org/10.1007/s10583-015-9243-5

TURRIÓN, C. Narrativa infantil y juvenil digital: ¿Qué ofrecen las nuevas formas al lector literario? 2014. 550 f. Tese (Doutorado em Didática da Língua e da Literatura) - Faculdade de Ciências da Educação, Universidade Autônoma de Barcelona, Barcelona, 2014.

YOKOTA, J.; TEALE, W. H. Picture books and the digital world: educators making informed choices. The Reading Teacher, v. 67, n. 8, p. 577-585, 2014. https://doi.org/10.1002/trtr.1262

ZAJĄC, M. Book apps for younger children: between a book and a computer game. Ars Educandi, Varsóvia, n. 10, p. 63-70, dez. 2013. https://doi.org/10.26881/ae.2013.10.04

ZIRALDO. Flicts. São Paulo: Editora Melhoramentos, 2014. Book app.

Recebido em: 10/06/2019

Aceito em: 01/09/2019 